\title{
Article \\ The Sensory Evaluation and Mechanical Properties of Functional Gummy in the Malaysian Market
}

\author{
Mohd Muzamir Mahat ${ }^{1 *}$, Awis Sukarni Mohmad Sabere 2*, Saiful 'Arifin Shafiee ${ }^{3}$, Mohd Azizi \\ Nawawi ${ }^{4}$, Hairul Hisham Hamzah ${ }^{5}$, Muhammad Afiq Fikri Md Jamil1, Nazreen Che Roslan', \\ Mohamed Izzharif Abdul Halim, ${ }^{4}$ Muhd Fauzi Safian ${ }^{4}$ \\ 1 School of Physics and Material Studies, Faculty of Applied Sciences, Universiti Teknologi MARA, 40450 \\ Shah Alam, Selangor, Malaysia; mmuzamir@uitm.edu.my; afiqf7@gmail.com; nazreen9504@gmail.com \\ 2 Kulliyyah of Pharmacy, International Islamic University Malaysia, Bandar Indera Mahkota, \\ 25200 Kuantan, Pahang, Malaysia; awissabere@iium.edu.my \\ 3 Kulliyyah of Science, International Islamic University Malaysia, Bandar Indera Mahkota, \\ 25200 Kuantan, Pahang, Malaysia; sabs@iium.edu.my \\ 4 School of Chemistry and Environment, Faculty of Applied Sciences, Universiti Teknologi MARA, 40450 \\ Shah Alam, Selangor, Malaysia; azizi_nawawi@uitm.edu.my; izzharif@uitm.edu.my; \\ muhdf956@uitm.edu.my \\ 5 School of Chemical Sciences, Universiti Sains Malaysia, 11800 Penang, Malaysia; hishamhamzah@usm.my \\ * Correspondence: mmuzamir@uitm.edu.my; +6019-3364616; awissabere@iium.edu.my, +6011-21481225
}

Abstract: The popularity of functional gummies has increased, which is evident from the growing line of functional gummies from almost every nutraceutical companies. Sensory evaluation serves the purpose of determining which brand of functional gummy would capture the largest market share. Texture profile analysis was used to determine the mechanical properties of functional gummies. The brands of functional gummies that came under the scope of this study were denoted as Brand A, B, C, D, E, F and G. Fourier Transform Infrared Spectroscopy was utilised to detect organic material and functional groups in the functional gummies. Texture profile analysis gave valuable insights into the gummies' mechanical properties which are cohesiveness, springiness, hardness, gumminess, and chewiness. Amongst the gummies that were studied, Brand F gummy has the highest value of cohesiveness of 0.92. Brand A gummy has a high springiness value of 1.0. Brand B gummy possesses the highest value of hardness, gumminess and chewiness of $12532.2 \mathrm{~g}$, 7617.6 N, and 6256.8 J, respectively. Qualitative sensory evaluation reveals that Brand G gummy has the best aesthetic qualities in terms of colour and appearance. Brand B gummy tastes the best while brand A gummy claims the top spot for gumminess and chewiness. Overall, the respondents in this study preferred brand A gummy over other brands.

Keywords: Food Analysis, Texture Profile Analysis, FTIR, Sensory Evaluation

\section{Introduction}

Functional or fortified gummy is a growing nutraceutical segment around the world. It is believed that the active ingredients in fortified food can improve our wellbeing by reducing the risks of diseases and rejuvenate the skin [1]. Typically, fortified gummies serve as a medium to deliver medications or nutrients. The rise in the demand for functional food amongst Malaysians is mainly driven by greater awareness for a healthier lifestyle. By definition, functional food is food that has one or more functional ingredients that can minimise disease risk and promotes extra health benefit in addition to the essential nutrition [2,3]. Depending on the product information labels, functional food claimed to boost immunity, minimise the risk of certain cancers, minimise the risk of cardiovascular disease, help in controlling body weight, enhance eyesight, improve memory and improve physical condition [4]. The types of typical functional food are listed in Table 1. 
Table 1. Types of Functional Food

\begin{tabular}{|c|c|c|}
\hline Types of functional food & Definition & Examples \\
\hline Fortified products & $\begin{array}{l}\text { Foods that are endowed with specific } \\
\text { food ingredients }\end{array}$ & Vitamin $C$ in fruit juice \\
\hline Enriched products & $\begin{array}{l}\text { Additional nutrients in food that are } \\
\text { absent in ordinary food }\end{array}$ & $\begin{array}{l}\text { Margarine with plant } \\
\text { sterol esters, }\end{array}$ \\
\hline Altered products & $\begin{array}{l}\text { Constituents of food that are } \\
\text { detrimental to health are removed, } \\
\text { reduced, or replaced with other } \\
\text { beneficial constituents }\end{array}$ & $\begin{array}{l}\text { Fibre as a liberator of } \\
\text { fat in meat products } \\
\text { and ice cream }\end{array}$ \\
\hline Non-altered products & Natural food with inherent nutrients & Natural food \\
\hline Enhanced products & $\begin{array}{l}\text { Food with reinforced natural } \\
\text { constituents via growth in particular } \\
\text { conditions, new food composition, } \\
\text { manipulation of genetic or otherwise. }\end{array}$ & $\begin{array}{c}\text { Eggs with increased } \\
\text { omega-3 by modifying } \\
\text { chicken feed }\end{array}$ \\
\hline
\end{tabular}

Source: [5]

As defined by the Institute of Food Technologists (IFT), sensory evaluation is a scientific method used to measure, analyses and interpret responses as perceived through the senses of sight, hearing, touch, smell and taste. For a sensory evaluation to be successful, sensory properties have to be in tandem with the physical, chemical, formulation and process variables [6]. Texture has a significant impact on the acceptability of foods, as the textural attributes perceived by the mouth influences the joy of eating [7]. Through word association tests, Alina Szczesniak has proved that texture is more crucial than the flavour for some foods. From this examination and other attributes, the standard rating scales of hardness, brittleness, chewiness, gumminess, viscosity, and adhesiveness were introduced to study food texture quantitatively, and the texture profile technique was propounded [8]. The most common analysis for the attribute mentioned is by using Texture Profile Analysis (TPA). TPA is a compression test that imitates actual mouth bites to food [9]. This analysis is mostly used to determine the strength of gel-like systems, as reported by Cappa et al., (2015) [10]. Ehsan and team evaluated gummy candies formulated with red beet extract as a colouring agent, Salix aegyptiaca distillate as a flavouring agent, and gellan gum as gelling co-agent. It was found that the hardness of the gummy $(60 \mathrm{~N})$ improved while gumminess $(15 \mathrm{~N})$ decreased as the gellan gum content in the formulation increases. Increment in the red beet extract resulted in increment of hardness as well [11]. Another study by Nasarudin and team used compression test to analyses the texture of noodle that was made through different formulation. They found that formulation that was made from high protein flour had the highest hardness in with a mean score of $3.13 \pm 0.06 \mathrm{~N}$. This stipulates that high protein flour contributed to the formation of gluten network [12].

For the past sixty years, the 9-point hedonic scale is commonly used as a sensory evaluation method to measure the acceptability of food. This scale was invented by David Peryam and his peers to understand the dietary preferences of U.S. marines. The scale ranges from 'extremely like' to 'extremely dislike' [13]. Rolim et al., (2019) utilises 9-point hedonic scale to study consumer's acceptability towards a healthier alternative to fruit juices which is juice blend containing isomaltooligosaccharides produced by fermentation with Weissella cibaria. Results showed good average acceptability in comparison to the natural orange juice, achieving scores of around six on a 9-point hedonic scale [14].

In Malaysia, there are a few companies that manufacture functional gummies. Each product has a unique texture and shape. The texture can be quantified by investigating its mechanical properties, in particular hardness, springiness, gumminess, chewiness and cohesiveness. Texture plays a vital role in gummy candies because the texture influences its chewability. Furthermore, each consumer has different expectations when it comes to the chewability of a functional gummy. The diversity of 
gummy texture is essential to meet the variety in consumers' sensory expectation. Studies of the mechanical properties of functional gummies are not abundant. Information regarding the gumminess and springiness of gummy is not readily available for consumers. The ability of a gummy to maintain its gumminess and springiness can be determined with mechanical testing. The aim of this study is to investigate the mechanical properties of common functional gummies in Malaysia. To understand the qualitative nature of the customers' taste and preference of the different gummies, a sensory evaluation was performed. The results from sensory evaluation could be used as insights to guide development and commercial strategy. Additionally, the major component and functional groups of the gummies were identified with a Fourier Transform Infrared Spectroscopy.

This study aim is to understand the qualitative nature of the customers' taste and preference of the different gummies through sensory evaluation. The results from sensory evaluation could be used as insights to guide development and commercial strategy. In addition, the mechanical properties of common functional gummies in Malaysia have been investigated. The major component and functional groups of the gummies were identified with a Fourier Transform Infrared Spectroscopy (FTIR).

\section{Results}

\subsection{Sensory evaluation}

Sensory evaluation of food is a scientific discipline that relies on statistical analysis and experimental design principle. It utilises the senses of smell, taste, sight, hearing, and touch. Sensory evaluation is performed by recording the responses of assessors when they test a product. After a thorough analysis, the results from the assessors' responses would give more insight and inferences regarding the tested product. A sensory test that was based on the 9-point hedonic scale was applied to distinguish the texture of gummies from different brands. Table 3 shows the images of gummies from different brands and angles.

Table 3 Images of gummies from different brands and angles

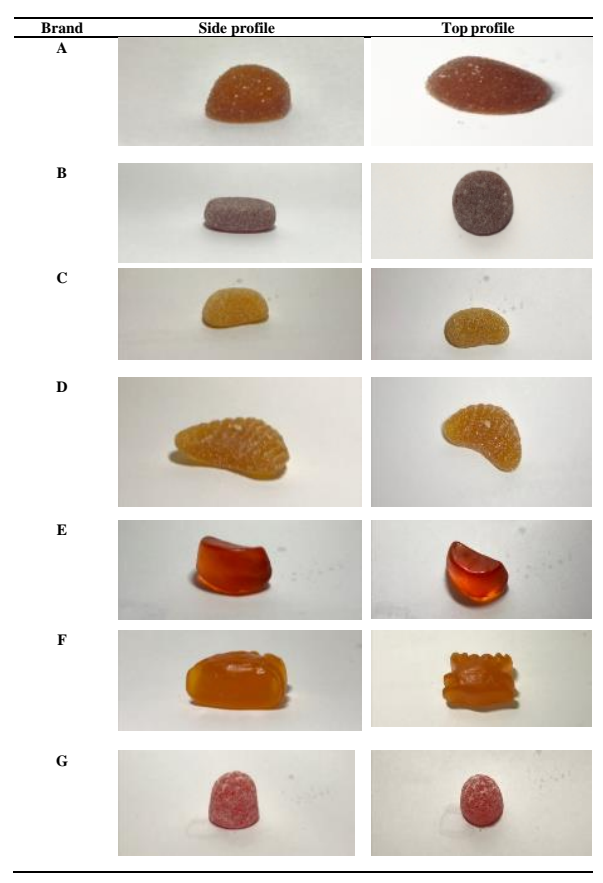


Visual perception, especially colour perception, dominates the way we perceive products in many ways [15]. Food colour is a primary characteristic of its palatability as it has a substantial impact on customer appetite[16]. For instance, Sheibani and partners studied the influent of colour intensity in saffron towards the likability. They discovered that most customers (88\%) favoured food with a high colour intensity resulting from the addition of saffron [17]. Additionally, colour is well integrated with the taste perception such as green is often linked with sourness, while red colours are associated with sweetness [18]. The results of the sensory evaluation on colour, appearance and taste are shown in Figure 1.

Figure 1(a) shows that 12 respondents agreed that Brand G gummy had the most appealing colour of all brands. Brand D is the second most preferred gummy based on the colour with ten votes. Brand F and Brand B gummies shared third place with eight votes. Besides colour, the physical shape of the gummy is a part of the gummy's appeal. Based on Figure 1(b), gummy with the physical shape was Brand $G$ with twelve votes. Eleven respondents chose Brand B as the second-best while Brand E took third place. In Figure 1(c), eleven respondents chose Brand B gummy as the tastiest, while the gummies from Brand D and Brand G were selected as the second and third tastiest gummy, respectively.

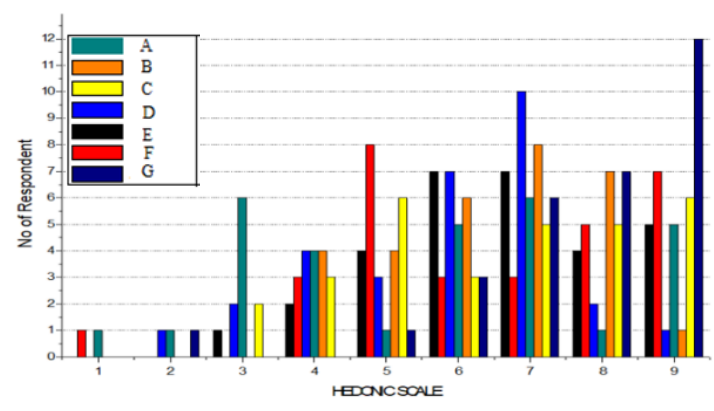

(a)

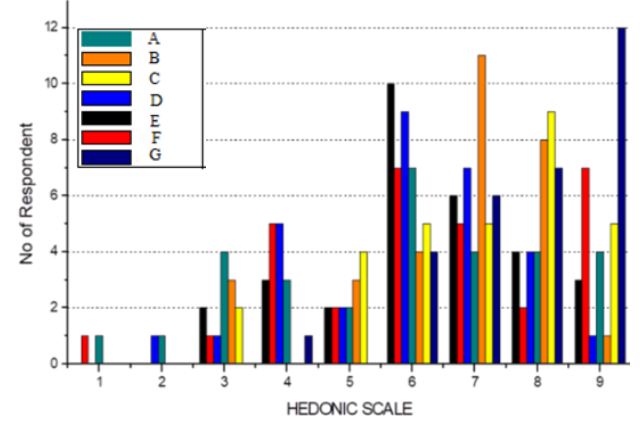

(b)

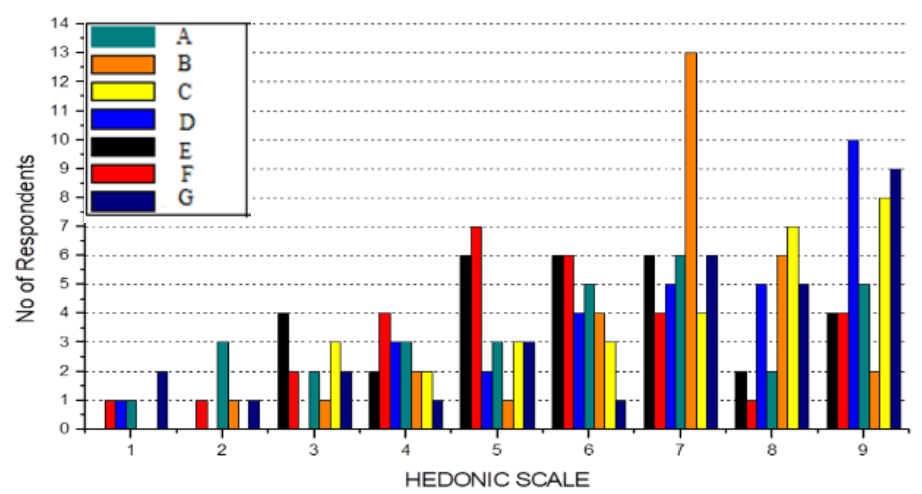

(c)

Figure 1. The overall hedonic scale of a) Colour, b) Appearance and c) Taste. 
Gumminess is the energy required to disintegrate a semi-solid food to a state ready for swallowing. It is the product of the semi-solid food's hardness multiplied by its cohesiveness. Food with profound gumminess has a low degree of hardness and a high degree of cohesiveness. Gelatine or agar is a gelation agent that imparts the signature soft and semi-solid texture to a gummy. The gumminess of a gummy is influenced by the amount of gelatine contained in the gummy [19]. Meanwhile, the chewiness is the expression of the gummy's springy texture when chewed. The overall hedonic scale of gumminess, chewiness and overall acceptability are shown in Figure 2. As illustrated in Figure 2(a), brand A gummy was the "gummiest" when compared to the other brands. Brand B was chosen as the second "gummiest" gummy with ten votes behind it.

The gummy's chewiness also indicates the amount of energy needed to chew the food before it can be swallowed. In general, chewiness is the sensory sensation of chewing due to elastic resistance from the food. The preferences of gummies' chewiness are shown in Figure 2(b). Brand E and Brand A gummies were the chewiest, as reported by eleven respondents for each brand. Taking the second spot for the chewiest gummy is Brand G gummy due to the preference of nine respondents. For Brand B gummy, eight (8) respondents opted for "dislike slightly" choice for its chewiness. Brand B gummy recorded the highest feedback of "dislike slightly" when compared to the other branded gummies. Overall acceptability is a parameter that informs which food sample meets the respondents' taste and preference the most. Food with the highest overall acceptability will most likely end up as the product that will be consumed. As shown in Figure 2(c), eleven out of thirty respondents favored brand A gummy as the most acceptable sample. The second most acceptable gummy was Brand B, with a tally of ten respondents. Three brands shared the third spot for overall acceptability, which are Brand D, Brand $C$ and Brand $G$ gummies with nine votes. Table 4 shows the overall results of which gummy brand was preferred based on a particular attribute.

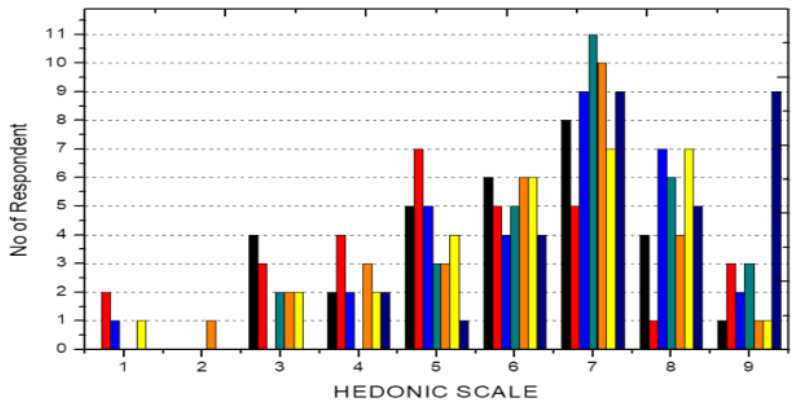

(a)

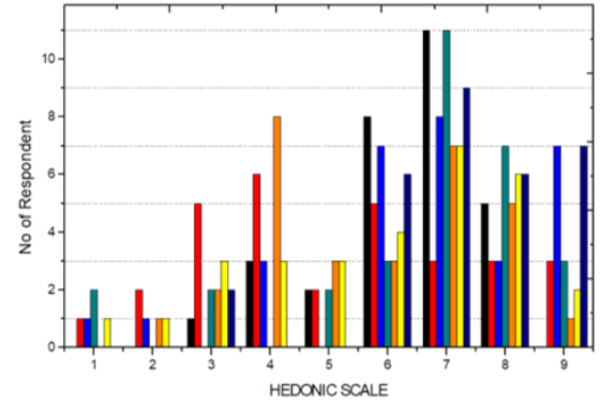

(b)

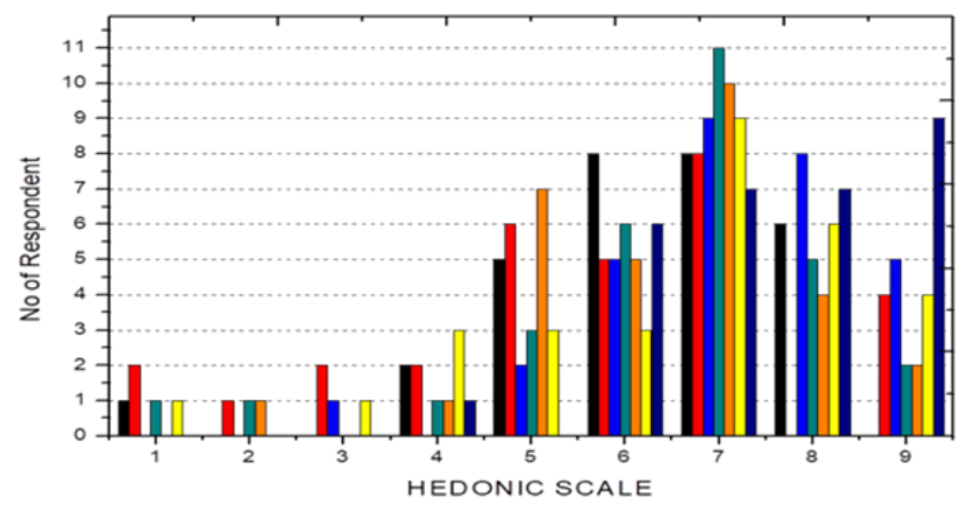

(c)

Figure 2 The overall hedonic scale of a) Gumminess, b) Chewiness and c) Overall acceptability. 
Table 4. The best gummy brand for a particular attribute.

\begin{tabular}{cc}
\hline Attribute & Brand \\
\hline Colour & Brand G \\
Appearance & Brand G \\
Taste & Brand B \\
Gumminess & Brand A \\
Chewiness & Brand A \\
Overall acceptability & Brand A \\
\hline
\end{tabular}

\subsection{Texture profile analysis}

As reported by Kim and Lee (2016), General Foods Corporation Technical Centre (1963) developed an instrumental test that measures the parameters of texture for food acceptability. The test involves two cycles of compression force to imitate mastication[20]. Texture profile can be used to measure the compression test on functional gummies. TPA is correlated to the parameters of sensory evaluation, such as hardness, cohesiveness, gumminess, and chewiness. The cohesiveness value of gummy according to their brand increased in the following order; Brand B (0.62), Brand A (0.9), and Brand F (0.92).

Meanwhile, the springiness value of the branded gummies increased in the following order; Brand B (0.82), Brand F (0.98), and Brand A (1.0). Brand B gummy recorded the highest value of hardness (12,532.3 g) followed by Brand $\mathrm{C}$ a hardness value of (6624.7 $\mathrm{g}$ ). The gummy with the lowest hardness value is the one from Brand A with a value of $586.4 \mathrm{~g}$. The higher the value of hardness, the firmer and tougher the food texture will be. Thus, more energy is required to deform it.

Next, the chewiness and gumminess of the gummies were quantified. Brand B gummy recorded the highest value for chewiness and gumminess at $6256.8 \mathrm{~J}$ and $7617.6 \mathrm{~N}$, respectively. Brand C gummy came in second with the value of $3585.4 \mathrm{~J}$ for chewiness and $4337.9 \mathrm{~N}$ for gumminess. The gummy with the lowest value for chewiness and gumminess is brand A gummy, which are $525.8 \mathrm{~J}$ and 527.3 $\mathrm{N}$ respectively. The hardness of a gummy is related to chewiness and gumminess. The harder the gummy, the firmer its structure will be. As a result, the gummy will be chewier and gummier. For brand A gummy, the value of its hardness, chewiness and gumminess were minimal. In turn, the gummy from this brand had high springiness and cohesiveness. Additionally, brand A gummy was softer compared to those from Brand B and Brand C. Figure 3 shows the springiness and cohesiveness values and sensory attributes of chewiness, hardness and gumminess. 


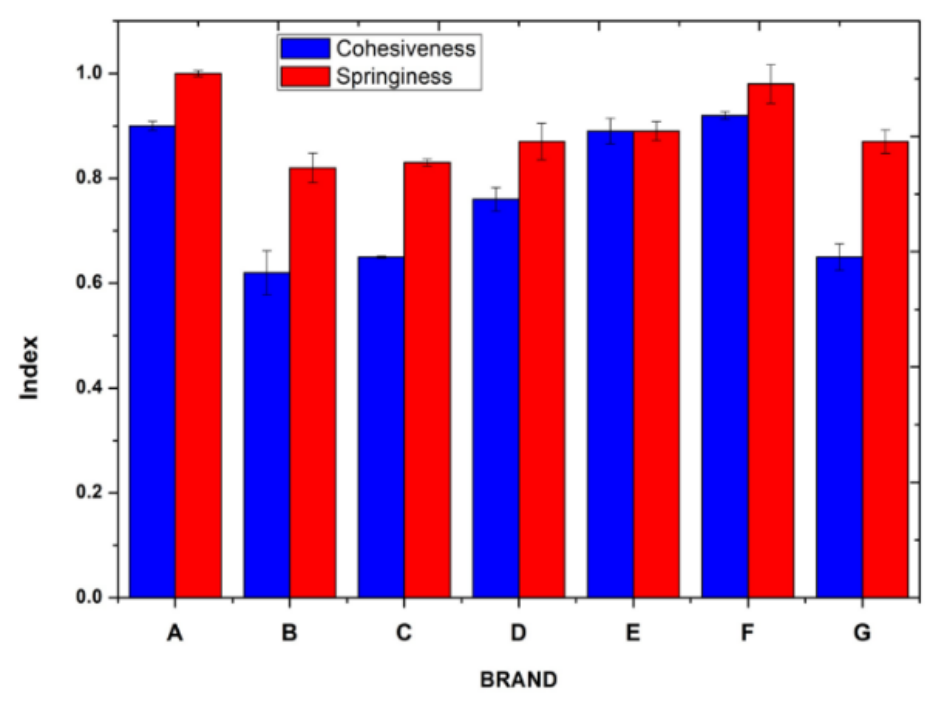

(a)

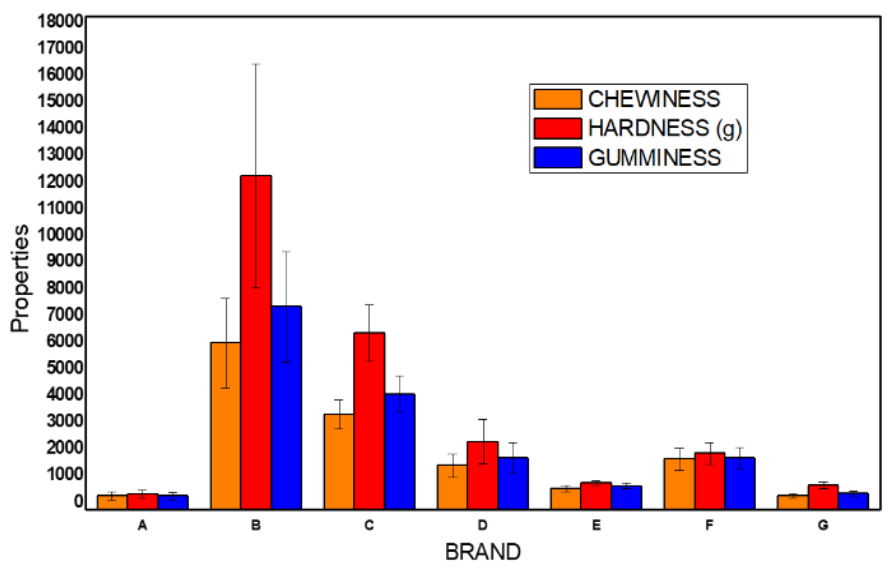

(b)

Figure 3 a) Springiness and Cohesiveness values of gummy from different brands, b) Sensory attributes of chewiness, hardness and gumminess.

2.3 Fourier transform infrared analysis of gummies

Gummy candies are made up mostly water, sugar and gelatine. The vibration of these components can be identified using Fourier Transform Infrared Spectroscopy (FTIR). FTIR analysis is a technique to detect polymeric, organic, and inorganic materials. The sample will absorb infrared radiation in the range of 600 and $4000 \mathrm{~cm}^{-1}$. The spectra of different gummies from different brands are presented in Figure 4. 


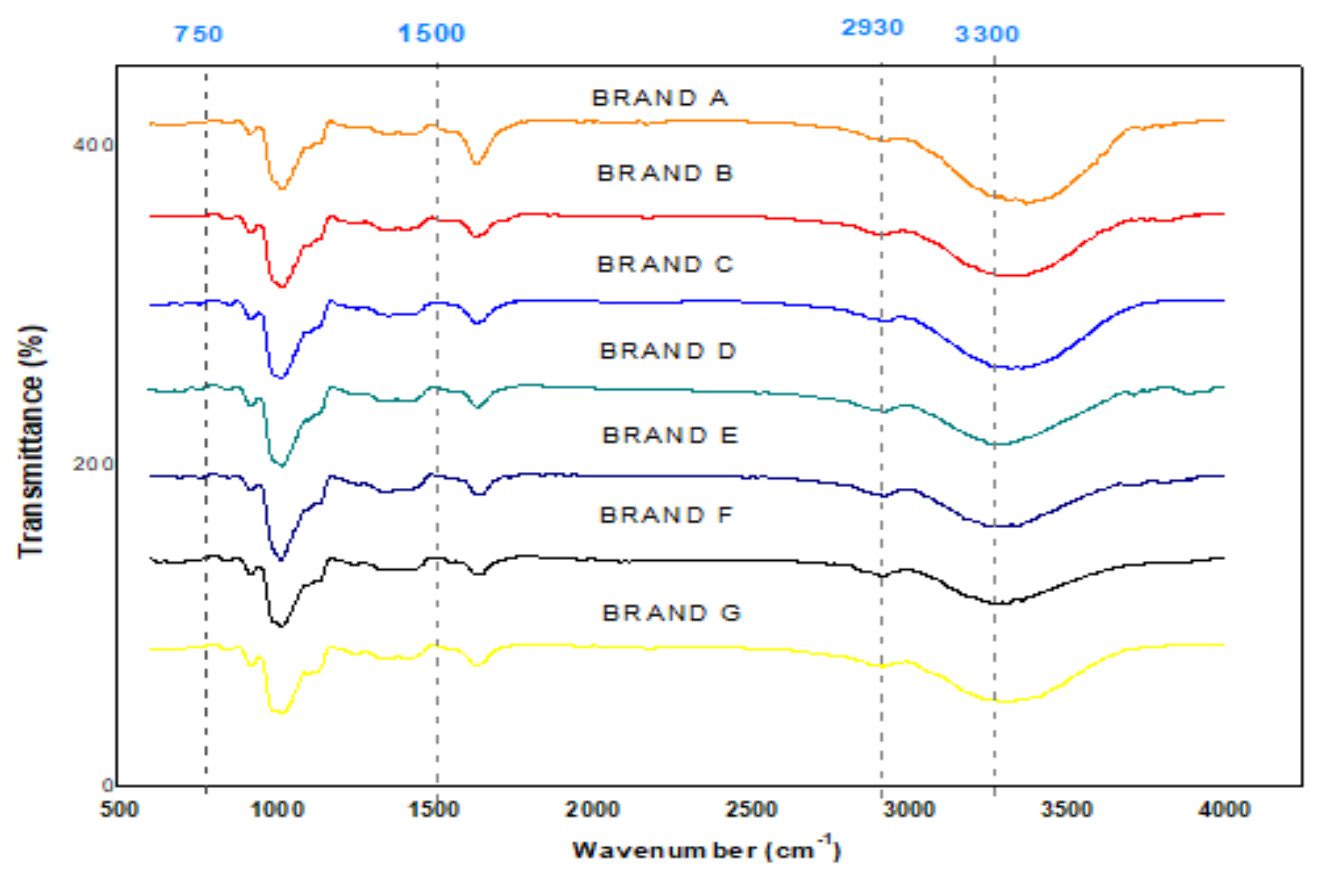

Figure 4. Spectra of different gummies from different brands.

As shown in Figure 4, the patterns of the FTIR spectrums are relatively similar to each other. The intensity of the peaks varies due to the different amount of ingredients that are unique to their particular brands. For the constituents of sugar, the bands of the spectrum can be observed in the range of $750 \mathrm{~cm}^{-1}$ to $1500 \mathrm{~cm}^{-1}$. In these sugar-related bands, the organic compound of sucrose can be observed at $993 \mathrm{~cm}^{-1}$ which represents the vibration of glycosidic links. The bands in the range from $750 \mathrm{~cm}^{-1}$ to $900 \mathrm{~cm}^{-1}$ are visible due to the presence of saccharides [21]. The peak range between 1100 and $1000 \mathrm{~cm}^{-1}$ is attributed from the C-O and C-O-C absorptions of the carbohydrate's parts [22].

\section{Materials and Method}

Seven different brands of gummies that are widely sold in local drug stores were purchased and tested. These gummies are categorised as functional food which contain vitamins and flavour. These brands, together with their functionality, are listed in Table 2.

Table 2 The brands of the gummies and their functionalities.

\begin{tabular}{cc}
\hline Brands & Functionality \\
\hline Brand A & Multivitamin + vegetables \\
Brand B & Multivitamin, minerals \\
Brand C & Immune system \\
Brand D & Vitamin C \\
Brand E & Vitamin C, vitamin D, zinc \\
Brand F & Vitamin C, Docosahexaenoic acid (DHA) \\
Brand G & Flavoured gummies \\
\hline
\end{tabular}

\subsection{Sensory evaluation}

An acceptance evaluation was conducted with a 9-point hedonic scale to assess the following features: colours, texture, appearance and overall acceptability. Thirty random consumers that represented the target market took part in this study. The inclusion criteria are age of 18-60 years old Malaysian, able to read and write in English. Meanwhile the exclusion criteria are smokers and having cold or flu during the experiments. The data from hedonic tests can reflect the preferences of 
consumers when presented with products from different manufactures. The 9-point hedonic scale is a standard technique for food evaluation (ISO 4121:2003).

\subsection{Mechanical properties}

TPA replicates the actual chewing experience. A TPA was performed on each gummy with a texturometer device (TA-XT2i Plus Texture Analyser, Stable Micro Systems, U.K.) with a flat $50 \mathrm{~mm}$ diameter probe. The samples were compressed twice at a rate of $10 \mathrm{~mm} \mathrm{~s}-1$ with a $20 \mathrm{~mm}$ return distance to allow the sample to deform without being penetrated. The testing parameters were: $24 \pm$ $2{ }^{\circ} \mathrm{C}$; two consecutive cycles of $50 \%$ compression; cross-head at a constant speed of $30 \mathrm{~mm} \mathrm{~min}^{-1}$ and a contact force of $10.0 \mathrm{~g}$. The recorded textural parameters are (1) hardness $(\mathrm{N})$ : Force required to compress the material by a given amount; (2) springiness ( $\mathrm{mm}$ ): elastic recovery that occurs when the compressive force is removed; (3) gumminess $(\mathrm{N})$; the energy required to break down a semi-solid food before it can be swallowed; (4) chewiness ( $\mathrm{N} \mathrm{mm}$ ); the energy required to chew a solid food into a state for swallowing; and (5) Cohesiveness; strength of the internal bonds in the sample.

\subsection{Functional group}

Functional group(s) of the gummy's molecular structure were determined using Fourier Transform Infrared (FTIR) Spectroscopy (FTIR Spectrometer Spectrum 400, Perkin-Elmer, USA). The samples were placed on the stage of FTIR, and the spectrum was recorded in transmittance. Spectra were recorded under mode between $600 \mathrm{~cm}^{-1}$ and $4000 \mathrm{~cm}^{-1}$ at $16 \mathrm{~cm}^{-1}$ resolution with 16 scans per spectrum. Background air spectrum was obtained before the commencement of any analysis. The Attenuated total reflectance (ATR) crystal diamond was cleaned with acetone and deionised water. After testing each sample, the diamond was rinsed with distilled water and ethanol.

\section{Conclusions}

The mechanical properties of selected functional gummies were examined with Texture Profile Analysis (TPA) and FTIR. FTIR study showed that all gummy samples have similar spectra despite each gummy from different brands had distinguishable hardness, chewiness, gumminess, cohesiveness and chewiness. The variation in these values could be caused by the differences in the gummies' preparation methodologies and the adhesive confectionery compositions. Sensory evaluation of the gummies showed that the respondents' preferences for the gummies were dependent on the gummies' texture. For instance, Brand A gummy, which has a high springiness value of 1.0, leads to the conclusion of respondents preferred this brand over the other brands. The results from the evaluation can be treated as a guide to formulate a gummy with acceptable qualities.

\section{Supplementary Materials: -}

Author Contributions: Conceptualization and Experimentation, M.M.M., A.S.M.S. and M.A.F. M.J.; writing - original draft preparation, M.M.M., A.S.M.S. and M.A.F. M.J.; writing - review and editing, M.M.M., A.S.M.S., S.A.S., M. A. N., H.H.H., M.A.F.M.J., N.C. R., M.I.A.H. and M. F. S. All authors have read and agreed to the published version of the manuscript.

Funding: This research was funded by the Universiti Teknologi MARA, 600-IRMI 5/3/GIP (010/2019) and International Islamic University Malaysia, RIGS16-288-0452.

Acknowledgements: Authors thank Food Technology Laboratory, Faculty of Applied Sciences, Universiti Teknologi MARA, Malaysia.

Conflicts of Interest: The authors declare no conflict of interest. 


\section{References}

[1] K. T. Phuah, G. Rezai, Z. Mohamed, and M. N. Shamsudin, Socio-Demographic Profile in Purchasing Natural and Synthetic Functional Foods in Malaysia, Int. J. Soc. Sci. Humanit. 2015, vol. 5, no. 7, pp. 604-607.

[2] J. Matos, C. Cardoso, N. M. Bandarra, and C. Afonso, Microalgae as healthy ingredients for functional food: A review. Food Funct. 2017, vol. 8, no. 8, pp. 2672-2685.

[3] J. de Toledo Guimarães, E. K. Silva, M. Q. de Freitas, M. A. de Almeida Meireles, and A. G. da Cruz, Non-thermal emerging technologies and their effects on the functional properties of dairy products, Curr. Opin. Food Sci. 2018, vol. 22, pp. 62-66.

[4] F. B. Bekoglu, A. Ergen, and B. Inci, The Impact of Attitude, Consumer Innovativeness and Interpersonal Influence on Functional Food Consumption, Int. Bus. Res. 2016, vol. 9, no. 4, p. 79.

[5] I. Gok and E. K. Ulu, Functional foods in Turkey: marketing, consumer awareness and regulatory aspects, Nutr. Food Sci. 2019, vol. 49, no. 4, pp. 668-686.

[6] M. K. Sharif, M. S. Butt, H. R. Sharif, and M. Nasir, Sensory Evaluation and Consumer Acceptability, Handb. Food Sci. Technol. 2017, pp. 362-386.

[7] K. Suebsaen, B. Suksatit, N. Kanha, and T. Laokuldilok, Instrumental characterization of banana dessert gels for the elderly with dysphagia, Food Biosci. 2019, vol. 32, p. 100477.

[8] K. Nishinari and Y. Fang, "Perception and measurement of food texture: Solid foods, J. Texture Stud. 2018, vol. 49, no. 2, pp. 160-201.

[9] H. S. Joyner (Melito), Explaining food texture through rheology, Curr. Opin. Food Sci. 2018, vol. 21, pp. 7-14.

[10] C. Cappa, V. Lavelli, and M. Mariotti, Fruit candies enriched with grape skin powders: Physicochemical properties, LWT - Food Sci. Technol. 2015, vol. 62, no. 1, pp. 569-575.

[11] E. Moghaddas Kia, S. Ghaderzadeh, A. Mojaddar Langroodi, Z. Ghasempour, and A. Ehsani, Red beet extract usage in gelatin/gellan based gummy candy formulation introducing Salix aegyptiaca distillate as a flavouring agent, J. Food Sci. Technol. 2020, vol. 57, no. 9, pp. 33553362.

[12] N. I. N. Nasruddin, M. S. M. Jamila, I. Zakariab, and I. Zubairia Saiful, Optimization of Noodle Formulation using Commercialized Empty Fruit Oil Carboxylmethyl Cellulose $(\mathrm{Cmc})$ and Flours with Different Protein Content, J. Teknol. 2018, vol. 80, no. 5, pp. 45-56.

[13] Y. Xia, J. Song, F. Zhong, J. Halim, and M. O'Mahony, The 9-point hedonic scale: Using RIndex Preference Measurement to compute effect size and eliminate artifactual ties, Food Res. Int. 2020, vol. 133, p. 109140.

[14] P. M. Rolim, Y. Hu, and M. G. Gänzle, Sensory analysis of juice blend containing isomaltooligosaccharides produced by fermentation with Weissella cibaria, Food Res. Int. 2019, vol. 124, pp. 86-92.

[15] A. R. Spencer, A. Primbetova, A. N. Koppes, R. A. Koppes, H. Fenniri, and N. Annabi, Electroconductive Gelatin Methacryloyl-PEDOT:PSS Composite Hydrogels: Design, Synthesis, and Properties, ACS Biomater. Sci. Eng. 2018, vol. 4, no. 5, pp. 1558-1567.

[16] A. Patras, Stability and colour evaluation of red cabbage waste hydroethanolic extract in presence of different food additives or ingredients, Food Chem. 2019, vol. 275, no. April 2018, pp. 539-548. 
[17] E. Sheibani, G. Matinfar, S. Jazaeri, and A. Mohammadi, Influences of sensory and nonsensory factors on consumer perception of saffroned products, Br. Food J. 2019, vol. 121, no. 11, pp. 2883-2900.

[18] J. Ammann, M. Stucki, and M. Siegrist, True colours: Advantages and challenges of virtual reality in a sensory science experiment on the influence of colour on flavour identification," Food Qual. Prefer. 2020, vol. 86, p. 103998.

[19] U. Čižauskaite, G. Jakubaityte, V. Žitkevičius, and G. Kasparavičiene, Natural ingredientsbased gummy bear composition designed according to texture analysis and sensory evaluation in vivo, Molecules 2019, vol. 24, no. 7.

[20] J. Kim and J. Lee, Korean Consumer Evaluation of Various Foods using Four Different Texture Lexicons, Journal of Sensory Studies 2016, vol. 31, pp. 314-327.

[21] O. Anjos, M. G. Campos, P. C. Ruiz, and P. Antunes, Application of FTIR-ATR spectroscopy to the quantification of sugar in honey, Food Chem. 2015, vol. 169, no. July, pp. 218-223.

[22] N. Cebi, M. Z. Durak, O. S. Toker, O. Sagdic, and M. Arici, An evaluation of Fourier transforms infrared spectroscopy method for the classification and discrimination of bovine, porcine and fish gelatins, Food Chem. 2016 vol. 190, pp. 1109-1115.

Sample Availability: Samples of the compounds ...... are available from the authors. 